\title{
A comparison of HALOE V19 with SAGE II V6.00 ozone observations using trajectory mapping
}

\author{
Gary A. Morris, ${ }^{1,2}$ James F. Gleason, ${ }^{3}$ James M. Russell III, ${ }^{4}$ Mark R. Schoeberl, ${ }^{3}$ \\ and M. Patrick McCormick ${ }^{4}$ \\ Received 18 May 2001; revised 23 October 2001; accepted 5 November 2001; published 12 July 2002.
}

[1] We apply trajectory mapping to an 8-year intercomparison of ozone observations from the Halogen Occultation Experiment (HALOE) (V19) and Stratospheric Aerosol and Gas Experiment (SAGE) II (V6.00) for the months March, May, June, September, October, and December from the period December 1991 to October 1999. Our results, which represent the most extensive such intercomparison of these two data sets to date, suggest a root-mean-square difference between the two data sets of $>15 \%$ below $22 \mathrm{~km}$ in the tropics and of $4-12 \%$ throughout most of the rest of the stratosphere. In addition, we find a bias with HALOE ozone low relative to SAGE II by $5-20 \%$ below $22 \mathrm{~km}$ between $40^{\circ} \mathrm{S}$ and $40^{\circ} \mathrm{N}$. Biases throughout most of the rest of the stratosphere are nearly nonexistent. Finally, our analysis suggests almost no drift in the bias between the data sets is observed over the period of study. In the course of our study, we also determine that the employment of the Wang-Cunnold criteria is still recommended with the V6.00 SAGE II ozone data. Results with the new versions of the data sets show significant improvement over previous versions, particularly in the elimination of midstratospheric biases and the elimination of the previously observed drifts in the biases between the data sets in the lower stratosphere. Since HALOE V19 and V18 ozone are very similar, these changes can likely be attributed to improvements in the SAGE II retrieval. INDEX TERMS: 3334

Meteorology and Atmospheric Dynamics: Middle atmosphere dynamics (0341, 0342); 3360 Meteorology and Atmospheric Dynamics: Remote sensing; 3394 Meteorology and Atmospheric Dynamics: Instruments and techniques; 0341 Atmospheric Composition and Structure: Middle atmosphere-constituent transport and chemistry (3334); KEYWORDS: ozone, remote sensing, atmospheric dynamics, modeling, validation,

atmospheric composition

\section{Introduction}

[2] An important problem in stratospheric research remains the nature of the mechanism responsible for the observed negative trends in midlatitude column ozone [Stolarski et al., 1991; Hollandsworth et al., 1995]. Ozone photochemistry is highly dependent upon altitude, with $\mathrm{NO}_{x}, \mathrm{HO}_{x}$, and $\mathrm{ClO}_{x}$ all serving as dominant loss mechanisms at different altitudes [e.g., Jackman et al., 1986]. As a consequence, understanding the cause of observed negative trends in the column requires knowledge of the changing shape of the ozone profile. While the Total Ozone Mapping Spectrometer (TOMS) instrument has provided a long and reliable global data record of the total column amount of ozone, it is unable to comment on the distribution of ozone

\footnotetext{
${ }^{1}$ Department of Physics and Astronomy, Valparaiso University, Valparaiso, Indiana, USA

${ }^{2}$ Now at Department of Physics and Astronomy, Rice University, Houston, Texas, USA.

${ }^{3}$ Laboratory for Atmospheres, NASA Goddard Space Flight Center, Greenbelt, Maryland, USA.

${ }^{4}$ Center for Atmospheric Sciences, Hampton University, Hampton, Virginia, USA.

Copyright 2002 by the American Geophysical Union. 0148-0227/02/2001JD000847\$09.00
}

within the column. To answer the question of the midlatitude trends in the vertical profile of ozone, data from other instruments are required.

[3] Two such instruments that supply high-resolution vertical profiles of ozone over a wide range of latitudes are the Halogen Occultation Experiment (HALOE) [Russell et al., 1993] and the Stratospheric Aerosol and Gas Experiment (SAGE) II [Mauldin et al., 1985; Chu et al., 1989]. Both instruments use the solar occultation technique to derive their measurements of ozone and other atmospheric constituents. (Further details about these instruments are given below.) To develop confidence in these two data records and to determine their value to diagnosing the midlatitude trends, we would like to evaluate how well they agree with another and to what extent that agreement changes with time.

[4] Recently, both the SAGE II and HALOE instrument teams released new versions of their data sets. While HALOE V19 ozone is very similar to the V18 data, the SAGE II V6.00 ozone represents a major revision to the SAGE II retrieval process. The evaluation of previous versions of these data have been the subject of numerous previous publications including the Stratospheric Processes and Their Role in Climate (SPARC) [1998] report, part of which addresses the issue of the consistency of the SAGE II (V5.96) and HALOE (V18) ozone data records. 
[5] Because of the measurement technique that both of these two instruments employ and the orbital parameters of the satellites on which they are carried, they do not often make their observations near the same geographic locations at the same time. Traditional validation efforts have often been frustrated, particularly in the tropics, where infrequent observations by both instruments lead to statistically insignificant results. As a result, the studies presented in the SPARC report struggle to produce statistically significant results when employing traditional coincident observations and zonal means to make comparison between the HALOE and SAGE II observations.

[6] In the remainder of this paper, we discuss the use of and employ trajectory mapping (TM) as described by Morris et al. [1995] to compare the two new versions (HALOE V19 and SAGE II V6.00) to one another as well as the previous versions (HALOE V18 and SAGE II V5.93) to one another. Our study includes the months of March, May, June, September, October, and December for the 8year period of December 1991 to October 1999, i.e., 6 months in each of 8 years for a total of 48 months of data. TM produces robust results for the comparison of ozone observations between HALOE and SAGE II over a range of latitudes from $\sim 60^{\circ} \mathrm{S}$ to $\sim 60^{\circ} \mathrm{N}$. We compare these two data sets using three statistical measures: the root-meansquare (RMS) difference, the bias (or offset) between the HALOE and SAGE II observations, and the drift in the bias as a function of time. Particularly important to the negative midlatitude trend in the vertical ozone profile is the drift in the bias statistic. While offsets between the instruments may be troubling, if the instruments exhibit no drift relative to one another, trend calculations performed using both data sets are more likely valid.

[7] In this paper we show that the latest versions of ozone observations from these two instruments exhibit little if any statistically significant drift with respect to one another over the 8-year record analyzed. In addition to examining the latest versions of these data sets, we present results from a comparison of the last publicly available versions of each data set (HALOE V18 and SAGE II V5.93) to establish a baseline by which to judge present versions of the retrieval algorithms. We note that the latest versions of the data sets have resulted in a significant reduction in the magnitude of the drift between HALOE and SAGE II, particularly in the lower tropical stratosphere, and a reduction of the earlier observed biases between the two data sets in the mid and upper stratosphere in the tropics and northern midlatitudes. Since HALOE V18 and V19 ozone profile data products are nearly identical, these results suggest that significant improvements have been realized in the SAGE V6.00 product over the V5.93 product.

\subsection{HALOE}

[8] HALOE rides on the Upper Atmosphere Research Satellite (UARS), which was deployed 14 September 1991 from the space shuttle Discovery. UARS was launched into an orbital plane inclined $57^{\circ}$ to the equator and circles the Earth at an altitude of $585 \mathrm{~km}$ with an orbital period of $\sim 96 \mathrm{~min}$. The orbit precesses at a rate of $5^{\circ}$ per day. Ten times per year, the satellite performs a yaw maneuver, which rotates the platform $180^{\circ}$ relative to its orbital velocity vector. These orbital parameters permit HALOE to make its observations from roughly $30^{\circ} \mathrm{S}$ to $70^{\circ} \mathrm{N}$ or $30^{\circ} \mathrm{N}$ to $70^{\circ} \mathrm{S}$ in each UARS "month," although the precise latitudes covered vary from month to month. For further information on the UARS platform, see Reber [1993].

[9] HALOE uses the solar occultation technique to make constituent measurements twice per orbit: once at sunrise and once at sunset. The instrument makes measurements with a vertical resolution of $\sim 2 \mathrm{~km}$, a horizontal field of view of $5 \mathrm{~km}$ (measured at the surface) perpendicular to the line of sight, and a limb path length of $300 \mathrm{~km}$ [Russell et al., 1993].

[10] Since UARS completes $\sim 15$ orbits each day, HALOE returns 30 profiles daily: 15 at sunrise, 15 at sunset. This measurement strategy provides good longitudinal coverage on two latitude circles each day, one corresponding to the sunrise locations, the other corresponding to the sunset locations. Latitude coverage of HALOE varies continuously over each UARS month.

[11] To derive constituent profiles, HALOE observes absorption bands in the infrared part of the spectrum between 2.45 and $10.04 \mu \mathrm{m}$, with $9.6 \mu \mathrm{m}$ being used for ozone retrievals [Russell et al., 1993]. By measuring the absorption lines in the spectrum of well-known background source, the sun, HALOE measurements are practically selfcalibrating and highly precise. In order to derive mixing ratios a temperature versus pressure profile is retrieved from HALOE data over the 5-85 km range using the $\mathrm{CO}_{2} 2.8 \mu \mathrm{m}$ band. Observations are tied to the National Center for Environmental Prediction (NCEP) temperature, pressure, and altitude data for altitudes below $35 \mathrm{~km}$ [Russell et al., 1993]. The presence of aerosols from the eruption of Mount Pinatubo complicates the retrieval procedure from launch through 1993, especially below $30 \mathrm{~km}$.

[12] Because of problems with the satellite's solar array, limited data were retrieved during June and early July 1992. Outside of this period, the satellite has performed admirably, and HALOE operated nearly continuously from the time at which it was turned on (about 4 weeks after launch). For further information, see Russell et al. [1993].

\subsection{SAGE II}

[13] The Stratospheric Aerosol and Gas Experiment II (SAGE II) was launched in October 1984 aboard the Earth Radiation Budget Satellite (ERBS). Like HALOE, SAGE II is a solar occultation instrument. SAGE II, however, makes its ozone observations in the visible portion of the spectrum, primarily using data from the center of the Chappuis absorption band measured by the instrument's $0.6 \mu \mathrm{m}$ channel. ERBS orbits the Earth along a circular path at a distance of $610 \mathrm{~km}$ above the surface of the Earth with an inclination of $56^{\circ}$. Over the course of $\sim 1$ month, SAGE II records observations at latitudes between $70^{\circ} \mathrm{S}$ and $70^{\circ} \mathrm{N}$, although the precise coverage varies from month to month. Like HALOE, SAGE II observations are made twice per orbit: once at sunrise and once at sunset. The SAGE II observations therefore are also limited to two narrow latitude bands each day. Further details on the SAGE II instrument are given by Mauldin et al. [1985] and on the original SAGE II retrieval algorithm by Chu et al. [1989]. The SAGE II instrument has been collecting data nearly continuously since the launch of the ERBS satellite. 
[14] Modeling of the original retrieval algorithm by $C h u$ et al. [1989] suggests that below $20 \mathrm{~km}$, aerosol contributes more than half of the signal at $0.6 \mu \mathrm{m}$. As a result, the presence of aerosols from the eruption of Mount Pinatubo made use of the SAGE II ozone data below $25 \mathrm{~km}$ nearly impossible for an extended period after the eruption. A study by H. J. Wang and D. M. Cunnold, which yielded Table 2.2 in the SPARC [1998] report, delineates periods and altitude ranges for which use of the SAGE II ozone data are not recommended. In this paper, we refer to these criteria the "Wang-Cunnold criteria." A recent failure of the instrument in summer of 2000 temporarily interrupted the data record after some 16 years of nearly flawless operations.

\subsection{Trajectory Mapping}

[15] We use TM to compare HALOE and SAGE II ozone. Since both instruments are solar occultation instruments, the two data sets are sparse when compared to data sets gathered from emission instruments such as the Microwave Limb Sounder (MLS) [Barath et al., 1993] or the Cryogenic Limb Array Etalon Spectrometer (CLAES) [Roche et al., 1993]. The nature of the occultation instrument data sets makes comparisons using traditional techniques difficult. For example, in the study of Morris et al. [2000], only $\sim 10 \%$ of the 1500 measurements made by HALOE and SAGE II in a 2-month period in 1995 could be correlated using a traditional coincidence approach. TM substantially increases the number of coincidences between the two satellite instruments and expands the latitude range of coincidences beyond traditional techniques. Furthermore, by taking into account dynamical variability, the trajectory technique often improves the statistics of coincident comparisons relative to more traditional approaches [Morris et al., 2000].

[16] TM has been described in detail by Morris et al. [1995] and thoroughly evaluated in a recent study by Morris et al. [2000]. In brief, TM takes advantage of quasi-conserved quantities following air parcel motion, namely, the mixing ratio and potential temperature. The first use of trajectory calculations to map satellite observations appeared in the mapping of the Halogen Occultation Experiment (HALOE) data set by Pierce et al. [1994].

[17] To create a synoptic trajectory map from satellite data, we initialize an air parcel in our trajectory model [Schoeberl and Sparling, 1994] at the time and location of each satellite observation. The model then isentropically advects these air parcels forward or backward in time to the time at which we desire an output synoptic map. In general, we employ a combination of forward and backward trajectory calculations as recommended by Morris et al. [2000]. By including both forward and backward trajectory calculations we minimize the impact of neglected diabatic processes and greatly enhance the density of coverage in our trajectory maps and hence the chances that we will be able to compare measurements from the two sparse satellite data sets. Furthermore, by accounting for dynamical changes in the atmosphere between observation times, TM provides better representations of the measured constituent fields than other schemes (e.g., asynoptic maps or fourier maps) [Morris et al., 1995].
[18] To compare ozone data from the SAGE II and HALOE instruments, we first create a series of synoptic trajectory maps from one of the data sets. We then sample the synoptic maps created from the first instrument at the times and locations of the observations of the second instrument. We consider those trajectory-mapped measurements appearing within a specified distance of the observations of the second instrument to be coincident. A maximum time difference between the observations is also specified to limit the duration of trajectory calculations. An example of the trajectory maps used in our analysis can be found in Plate 1 of Morris et al. [2000]. This plate depicts both the coverage obtained using 14-day trajectories with HALOE and SAGE II data as well as the number of coincidences that can be achieved between the instruments by using the trajectory mapping technique. Details on the specific parameters chosen for our study are provided below.

[19] Ideally, we would create a trajectory map at the time of each new observation by the second instrument. In so doing, we account for movement of air parcels in which the first instrument made its observations. Because of the number of observations included in our 8-year study period, however, this practice is impractical. Instead, we use data from both instruments to produce trajectory maps twice per day, once at midnight and once at noon universal time (UT). All new observations from the one instrument appearing in a given trajectory map are then compared with the surrounding, trajectory-mapped measurements from the other instrument. The "new" observations are thus advected for less than 12 hours by the model, a timescale short enough that it should have little to no negative impact on our statistical comparisons of the data from the two instruments [Morris et al., 1995].

\section{Methodology}

[20] In this section we detail the specific parameters of the trajectory technique that we employ to compare HALOE V19 to SAGE II V6.00 ozone data and HALOE V18 to SAGE II V5.93. Our study examines data from the months of March, May, June, September, October, and December for the 8-year period of December 1991 to October 1999.

[21] In order to yield global coverage in our trajectory maps of HALOE and SAGE II data we use isentropic trajectories of up to 14 days duration as calculated with balanced winds computed from meteorological data provided by the National Centers for Environmental Prediction (NCEP) [Newman et al., 1988; Randel, 1987]. Using calculations of up to 14 days duration enables TM to produce coincidences between the two instruments at nearly all latitudes, a result unattainable by traditional approaches [e.g., SPARC, 1998]. For each month included in the study, we initialize and advect air parcels corresponding to all observations made during the period from 2 weeks prior to the beginning of the month through 2 weeks after the end of the month. Each observation taken in the month of interest may be correlated with observations from the other instrument made within a 4-week period centered on the time of the observation. By using a combination of forward and backward trajectory calculations we tend to reduce the bias that can be introduced when using isentropic trajectory calculations to validate a trace gas with a vertical gradient 


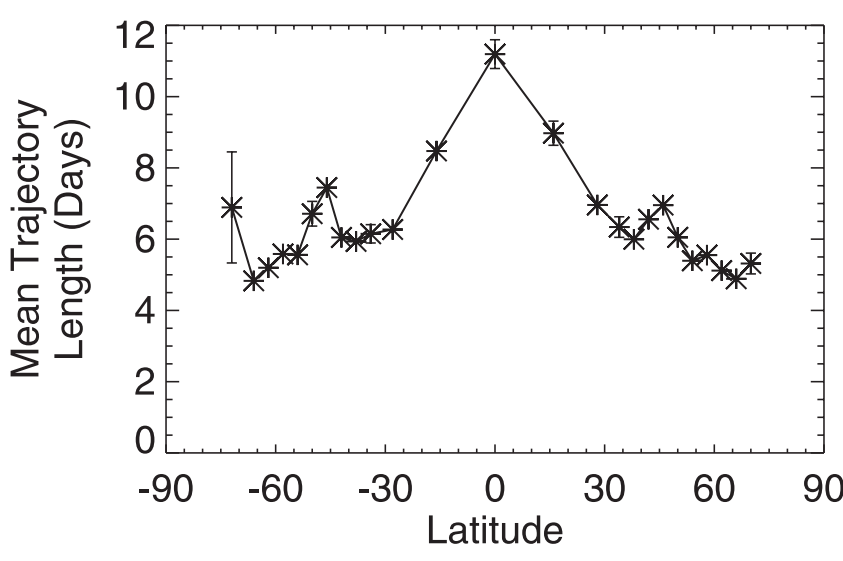

\section{Forward/Backward Combined 1.5- to 14-day NCEP trajectory runs}

Figure 1. Trajectory calculation time as a function of latitude averaged over the nine levels in the study. The error bars represent one standard deviation as established by the variance in the trajectory length with altitude. These results are for the 8-year (December 1991 to October 1999) trajectory mapping intercomparison of HALOE and SAGE II ozone observations.

such as ozone [Morris et al., 2000]. While the isentropic approximation degrades with the length of the trajectory calculations, numerous studies have cited a period of 710 days as a reasonable upper limit on isentropic trajectory analyses [Schoeberl and Sparling, 1994; Sutton et al., 1994; Morris et al., 1995]. Morris et al. [2000] show that by using a combination of forward and backward trajectories to construct trajectory maps, even calculations of 10-14 days can be employed in validation efforts with small to negligible impact on the bias statistic $(<2 \%$ for the water vapor study presented in their paper).

[22] We run isentropic trajectories at eight vertical levels spanning an altitude range from $\sim 15$ to $\sim 40 \mathrm{~km}$ (precisely, the trajectories were run on the $400,450,500,550,600$, 800,1000 , and $1200 \mathrm{~K}$ potential temperature surfaces). Again to minimize errors introduced in TM validation efforts, we employ a coincidence criterion of $400 \mathrm{~km}$ as recommended by the results of previous studies [Morris et al., 2000; Rex et al., 1998] and as is consistent with the limb path length of the occultation instruments.

[23] We initialize each HALOE observation in a tight cluster of five parcels (forming a cross with parcel separation of $40 \mathrm{~km}$ ) and advect these particles forward and backward in time to the location of the SAGE II observations. We repeat the process by initializing each SAGE II observation as a tight cluster of five parcels and advect the SAGE II air parcels forward and backward in time to the location of the HALOE observations. The trajectory model is run for and statistics are computed using trajectories of $1.5,3,5,7,10$, and 14 days duration. TM coincidences are given a statistical weight equal to the inverse of the trajectory duration. For example, 1.5-day trajectory correlations are given a statistical weight of $1 / 1.5$, while 3 -day trajectory correlations are given a weight of $1 / 3$ in computing the root-mean-square (RMS) difference and bias statis- tics (see below for more details in their computation). In this way, we heavily weight our statistics toward the shortest available TM coincidences in each latitude band and rely on the longest trajectories only in those latitude bands where no shorter trajectories produce coincidences. The overall results presented in this paper use results generated from both the run in which HALOE parcels were advected to the location of SAGE II observations as well as the run in which SAGE II parcels were advected to the location of the HALOE observations. Differences between the results computed from these two scenarios provide an estimate of the uncertainty in statistics.

[24] Figure 1 shows the mean duration of all trajectories that result in coincidences as a function of latitude and as computed for trajectories on the $800 \mathrm{~K}$ potential temperature surface. (We note that analysis of this same quantity on other potential temperature surfaces shows little difference with the $800 \mathrm{~K}$ surface, though trajectories in the lower tropical stratosphere tend to run slightly longer ( $\sim 1$ day) than those at 800 K.) Error bars in Figure 1 represent one standard deviation difference from the mean as calculated from the data within each latitude bin. Where no error bars appear, the error bars are smaller than the size of the plot symbol. The boundaries of the latitude bins appear in Table 1 and are the same as those used to analyze our three statistics (RMS, bias, and drift) outlined below. With the exception of the tropics $\left(24^{\circ} \mathrm{S}\right.$ to $\left.24^{\circ} \mathrm{N}\right)$, mean trajectory calculations are on the order of 5-7 days. Even within the tropics (except from $8^{\circ} \mathrm{S}$ to $8^{\circ} \mathrm{N}$ ) the trajectories are of less than 7-10 days duration, a previously acknowledged acceptable limit for isentropic trajectory calculations. Only in the latitude bin closest to the equator do our trajectory calculations frequently exceed the 7-10 days duration. Results from Morris et al. [2000], however, suggest that calculations of up to 14 days can be statistically useful in evaluating the agreement between two data sets. Figure 1 therefore suggests that on average, the trajectory data employed to produce our figures and the conclusions outlined below should not be discounted for having been produced with unreasonably long trajectory calculations.

[25] We employ three statistical tests in our evaluation of the agreement between the HALOE and SAGE II ozone data records: the root-mean-square (RMS) difference, the bias (or offset) between the instruments, and the drift in time of the bias. In computing each statistic, we first bin the data

Table 1. Latitude Boundaries Used to Compute the Zonal Means of the Statistics Presented in the Figures of this Paper

\begin{tabular}{lc}
\hline $\mathrm{SH}$ & $\mathrm{NH}$ \\
\hline $74^{\circ}-68^{\circ} \mathrm{S}$ & $68^{\circ}-72^{\circ} \mathrm{N}$ \\
$68^{\circ}-64^{\circ} \mathrm{S}$ & $64^{\circ}-68^{\circ} \mathrm{N}$ \\
$64^{\circ}-60^{\circ} \mathrm{S}$ & $60^{\circ}-64^{\circ} \mathrm{N}$ \\
$60^{\circ}-56^{\circ} \mathrm{S}$ & $56^{\circ}-60^{\circ} \mathrm{N}$ \\
$56^{\circ}-52^{\circ} \mathrm{S}$ & $52^{\circ}-56^{\circ} \mathrm{N}$ \\
$52^{\circ}-48^{\circ} \mathrm{S}$ & $48^{\circ}-52^{\circ} \mathrm{N}$ \\
$48^{\circ}-44^{\circ} \mathrm{S}$ & $44^{\circ}-48^{\circ} \mathrm{N}$ \\
$44^{\circ}-40^{\circ} \mathrm{S}$ & $40^{\circ}-44^{\circ} \mathrm{N}$ \\
$36^{\circ}-40^{\circ} \mathrm{S}$ & $36^{\circ}-40^{\circ} \mathrm{N}$ \\
$32^{\circ}-36^{\circ} \mathrm{S}$ & $32^{\circ}-36^{\circ} \mathrm{N}$ \\
$32^{\circ}-24^{\circ} \mathrm{S}$ & $32^{\circ}-24^{\circ} \mathrm{N}$ \\
$24^{\circ}-8^{\circ} \mathrm{S}$ & $24^{\circ}-8^{\circ} \mathrm{N}$ \\
$8^{\circ} \mathrm{S}-8^{\circ} \mathrm{N}$ &
\end{tabular}


both horizontally and vertically. Horizontally, we bin the data every $4^{\circ}$ latitude between $68^{\circ} \mathrm{S}$ and $32^{\circ} \mathrm{S}$ and between $32^{\circ} \mathrm{N}$ and $70^{\circ} \mathrm{N}$ and use somewhat larger bins in the tropics between $32^{\circ} \mathrm{S}$ and $32^{\circ} \mathrm{N}$. The precise boundaries of the latitude bins are provided in Table 1 and are selected in attempt to yield a more even distribution of the coincident observations between the latitude bins than would be produced by equally spaced latitude bins. Vertically the data are in $\sim 2.5 \mathrm{~km}$ bins (i.e., the potential temperature surfaces listed above).

[26] The RMS difference between the HALOE and SAGE II data records is expressed as a percentage of the SAGE II observations and is computed as follows:

$$
\operatorname{RMS}(\%)=100 \frac{\sum_{i=1}^{N}\left(w_{i} \sqrt{\left(H_{i}-S_{i}\right)^{2}} / S_{i}\right)}{\sum_{i=1}^{N} w_{i}}
$$

where $N$ is the total number of coincidences in each bin, $H_{i}$ is the HALOE data, $S_{i}$ is the SAGE II data, and $w_{i}$ is the weight given due to the maximum trajectory length (the inverse of the trajectory duration in days that results in each coincidence: $1 / 1.5,1 / 3,1 / 5$, etc.). We compute the RMS statistic defined above in two ways. First, we define $H_{i}$ as the mean of the trajectory mapped HALOE observations that satisfy our coincidence criteria around the $i$ th SAGE II observation $\left(S_{i}\right)$. We then recompute the RMS statistic defining $S_{i}$ as the mean of the trajectory mapped SAGE II observations that satisfy our coincidence criteria around the $i$ th HALOE observation $\left(H_{i}\right)$. The RMS statistic that appears in the figures in this paper is the statistically weighted mean of the RMS statistic as computed both ways using the statistical weights (as defined above by the inverse of the maximum trajectory length). In the following figures, we have converted potential temperature to pressure altitude by using the mean pressure of the air parcels advected into each bin.

[27] We compute the bias $(\Delta)$ of HALOE relative to SAGE II expressed as a percentage of SAGE II observations through the relationship

$$
\Delta(\%)=100 \frac{\sum_{i=1}^{N}\left(w_{i}\left(H_{i}-S_{i}\right) / S_{i}\right)}{\sum_{i=1}^{N} w_{i}}
$$

where the variables are defined as for the RMS statistic above. Although we compute the bias relative to the SAGE II data, we in no way imply that the HALOE data are more or less accurate than the SAGE II data. We choose this formulation of the bias to be consistent with previous studies [e.g., SPARC, 1998] in which all other ozone data sets are compared to the SAGE II data. As is the case with the RMS statistic, the HALOE and SAGE II data are binned by latitude and altitude before computation of $\Delta(\%)$.

[28] Finally, we compute the drift in the bias statistic using a simple, least squares weighted linear regression model of the bias statistic with time. For each latitude/

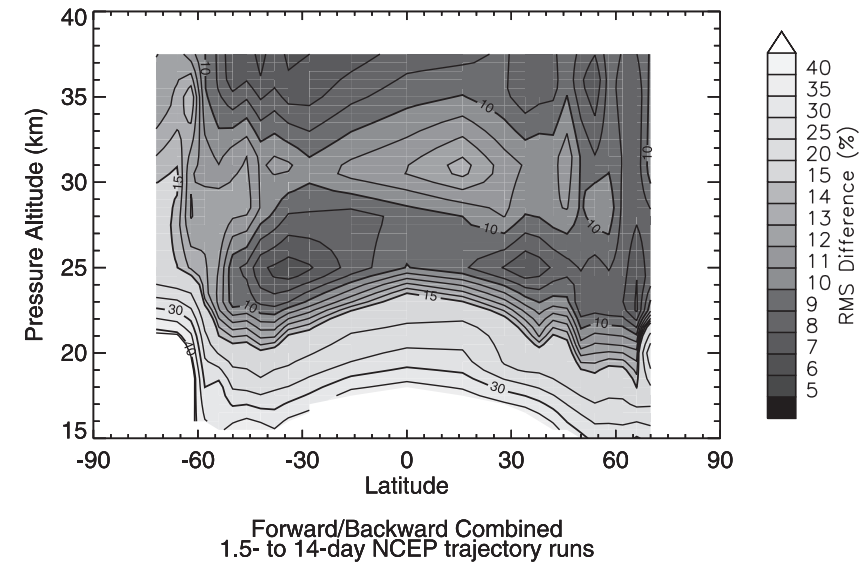

Figure 2. Zonal mean root-mean-square (RMS) differences (see text for definition) between HALOE V19 and SAGE II V6.00 ozone observations as computed from an 8year, 6-month intercomparison (December 1991 to October 1999) using trajectory mapping. Large differences $(>15 \%)$ are observed below $22 \mathrm{~km}$ with smaller differences in the middle stratosphere.

altitude bin, we create a time series from the bias data. We then fit a straight line of the form

$$
\Delta_{t}(\%)=A t+B,
$$

where $\Delta_{t}$ is the modeled bias at time $t$ and $A$ represents the drift in the bias and is computed using the formulation

$$
A=\frac{\left(\sum_{i=1}^{N} w_{i} t_{i}^{2}\right)\left(\sum_{i=1}^{N} w_{i} \Delta_{i}\right)-\left(\sum_{i=1}^{N} w_{i} t_{i}\right)\left(\sum_{i=1}^{N} w_{i} t_{i} \Delta_{i}\right)}{\left(\sum_{i=1}^{N} w_{i}\right)\left(\sum_{i=1}^{N} w_{i} t_{i}^{2}\right)-\left(\sum w_{i} t_{i}\right)^{2}}
$$

where $\Delta_{i}$ is the bias (as defined above) of $H_{i}$ relative to $S_{i}$ at time $t_{i}$

\section{Results and Analysis}

[29] Figure 2 shows the zonal mean, RMS differences between SAGE II V6.00 and HALOE V19 ozone measurements combined for the entire 8-year study period. RMS differences between HALOE and SAGE II ozone observations below $22 \mathrm{~km}$ exceed $15 \%$. Above $22 \mathrm{~km}$, the RMS differences are roughly $4-12 \%$ from $60^{\circ} \mathrm{S}$ to $60^{\circ} \mathrm{N}$ latitude, with higher values poleward of $60^{\circ}$ and a region of slightly higher values around $15^{\circ} \mathrm{N}$ latitude and $31 \mathrm{~km}$ altitude. The RMS differences between HALOE V19 and SAGE II V6.00 show only minor changes from those found between HALOE V18 and SAGE II V5.93 (not shown, but which reveals a slightly higher $(\$ 1 \%)$ RMS statistic above $22 \mathrm{~km}$ from $60^{\circ} \mathrm{S}$ to $60^{\circ} \mathrm{N}$ ).

[30] Previous validation efforts have shown results generally in agreement with our findings in Figure 2, though no previous analyses have been carried out over as extensive a range of observations as presented in this work. A previous trajectory analysis of selected SAGE II ozone profiles in the northern midlatitudes $\left(45^{\circ}-50^{\circ} \mathrm{N}\right)$ during 1993 showed $10-$ 
a)

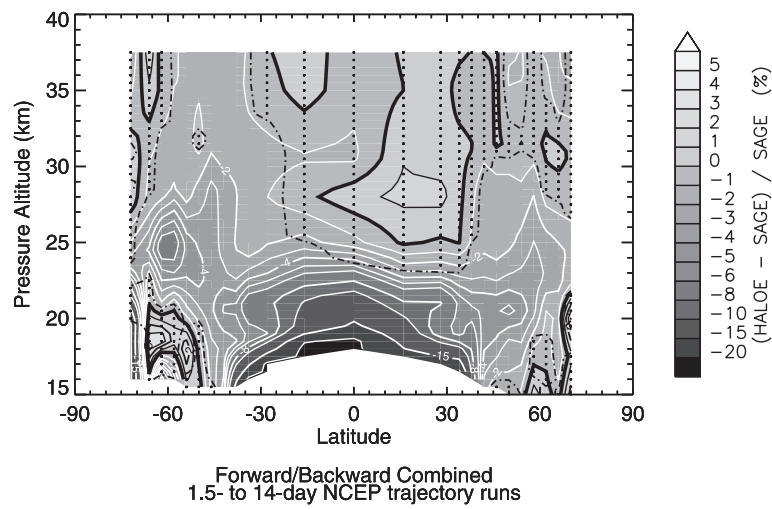

b)

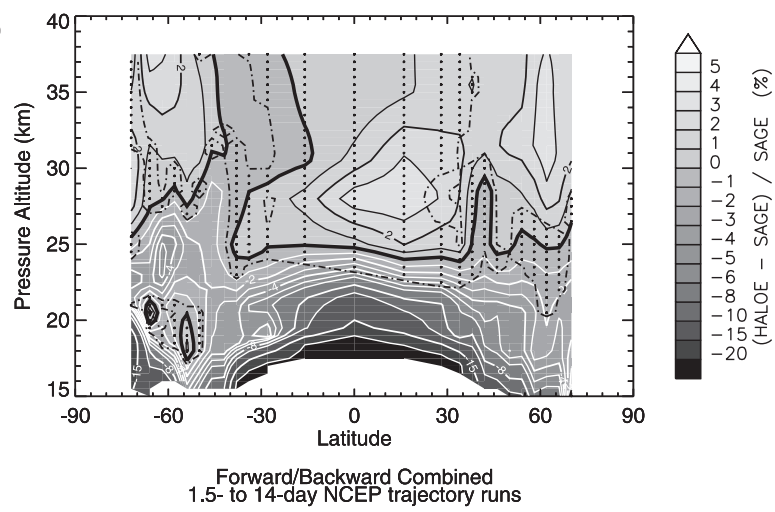

Figure 3. Trajectory mapping results of the zonal mean bias statistic (see text for definition) for ozone observations of HALOE relative to SAGE II for the same study period as in Figure 2. The regions bounded by the dash-dotted lines and containing stripes of vertical stars are regions not statistically significantly different from $0 \%$, as defined in the text. (a) HALOE V19 and SAGE II V6.00. (b) HALOE V18 and SAGE II V5.93. We see biases of $4-20 \%$ of HALOE low compared to SAGE II below $22 \mathrm{~km}$ in the tropics and subtropics. Throughout most of the remainder of the stratosphere, only small differences are observed.

$20 \%$ differences above $\sim 22 \mathrm{~km}[\mathrm{Lu}$ et al., 2000] between new observations and those advected by their dynamical model. These differences are somewhat larger on average than those that we find between HALOE and SAGE II at the same latitudes.

[31] Figure 3a shows the bias of HALOE V19 ozone data as compared to SAGE II V6.00. The regions marked by dash-dotted lines and containing vertical stripes of stars represent regions of statistically insignificant differences: In these regions the bias is smaller than the difference between the biases computed with the HALOE to SAGE II trajectory maps and those computed with the SAGE II to HALOE trajectory maps, as described earlier. As can be seen in Figure $3 \mathrm{a}$, the trajectory results indicate a bias of $5-20 \%$ (with HALOE lower than SAGE II) below $22 \mathrm{~km}$ in the tropics, subtropics, and lower midlatitudes $\left(40^{\circ} \mathrm{S}-40^{\circ} \mathrm{N}\right)$. A localized region with HALOE biased 4-8\% low compared to SAGE II also appears at $60^{\circ} \mathrm{S}$ and $25 \mathrm{~km}$. Throughout most of the remainder of the stratosphere, little to no bias is observed between the data sets from $60^{\circ} \mathrm{S}$ to $60^{\circ} \mathrm{N}$. These results differ from those found in the comparison of HALOE V18 with SAGE II V5.93 shown in Figure 3b. We note that with the new versions of these data used in the production of Figure 3a, the regions in Figure 3b in which HALOE appears biased high compared to SAGE II (in the mid to upper stratosphere: $10^{\circ} \mathrm{S}-30^{\circ} \mathrm{N}, 26-32 \mathrm{~km} ; 60^{\circ} \mathrm{N}$ above $27 \mathrm{~km}$; and $60^{\circ} \mathrm{S}$ above $32 \mathrm{~km}$ ) have almost entirely disappeared.

[32] We also note that between Figures $3 \mathrm{~b}$ and $3 \mathrm{a}$, we see large decreases in the bias at latitudes between $40^{\circ}$ and $60^{\circ}$ below $20 \mathrm{~km}$ in both hemispheres. This decrease in the bias suggests some improvement has been made in the lower stratosphere at these latitudes by the latest SAGE II retrieval. Since changes between HALOE V18 and V19 are relatively minor, most of the observable differences between Figures $3 b$ and $3 a$ can be attributed to changes in the SAGE II retrieval algorithm. (In fact, we have examined HALOE V19 versus SAGE V5.93 maps and find little difference from the maps of HALOE V18 versus SAGE V5.93 shown in this paper.) In the tropics and subtropics between $30^{\circ} \mathrm{S}$ and $30^{\circ} \mathrm{N}$ below $24 \mathrm{~km}$, we observe little change in the bias statistic.

[33] Numerous previous validation studies have found biases similar to those that appear in Figure 3. Cunnold et al. [2000] found differences of more than $10 \%$ between SAGE II (V5.96) and HALOE ozone observations in the lower stratosphere (below $20 \mathrm{~km}$ ) with HALOE low compared to SAGE II and with the largest differences occurring in the tropics. Such results seem consistent with Figure 3, where we also find the largest differences, well exceeding $10 \%$ in the tropical lower stratosphere, with HALOE again low compared to SAGE II. Comparisons of SAGE II observations with ozonesondes have repeatedly shown SAGE II observations exceeding sonde observations in the lower stratosphere by 5-20\% [SPARC, 1998; Veiga et al., 1995]. Comparisons of the SAGE II ozone observations with lidar show SAGE II high by $4.5-9.5 \% \pm 4 \%$ at $20 \mathrm{~km}$ [SPARC, 1998] and by around $2.5 \%$ in a 3-year study comparing SAGE II ozone to the lidar in Lauder, New Zealand [Brinksma et al., 2000]. Results shown in Figure 3a show $1-5 \%$ differences around the latitude of Lauder $\left(45^{\circ} \mathrm{S}\right)$, in rough agreement with the Lauder lidar. Comparisons with Umkehr data show SAGE II high by $10 \%$ below layer $3(\sim 15 \mathrm{~km})$ [SPARC, 1998] and SAGE II low compared to Umkehr in layers 5 and $6(\sim 23$ to $\sim 32 \mathrm{~km})$ by 3-8\% [Newchurch et al., 1995]. At $18 \mathrm{~km}$ we find SAGE II higher than HALOE by similar amounts. Above $24 \mathrm{~km}$ we generally find HALOE V18 higher than SAGE II V5.93 by $0-4 \%$ (Figure $3 \mathrm{~b}$ ), but little to no bias $( \pm 2 \%)$ is evident between HALOE V19 and SAGE II V6.00 at these altitudes (Figure 3a). The only notable exception in the latter case is a small region centered at $25 \mathrm{~km}$ and $60^{\circ} \mathrm{S}$ latitude where differences of HALOE of up to $4 \%$ lower than SAGE II can be found.

[34] SPARC [1998] compares SAGE II V5.96 with HALOE V18 and finds general agreement of the two ozone data sets to within $5 \%$ between 25 and $50 \mathrm{~km}$. Below $22 \mathrm{~km}$, however, differences up to and exceeding $20 \%$ are reported. A study by R. J. Atkinson and S. M. Hollandsworth produced Figure 2.32 of SPARC [1998], which shows a comparison of HALOE and SAGE II ozone observations using coordinate mapping $(\mathrm{CM})$, a dynamical approach to 
a)

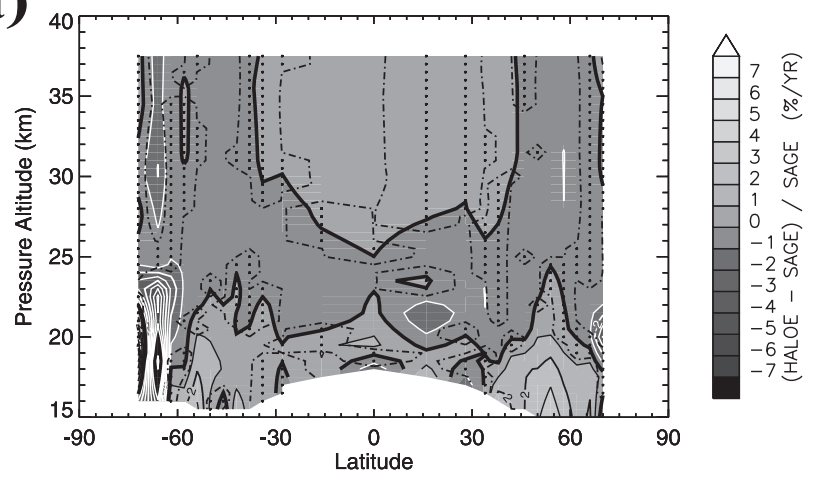

b)

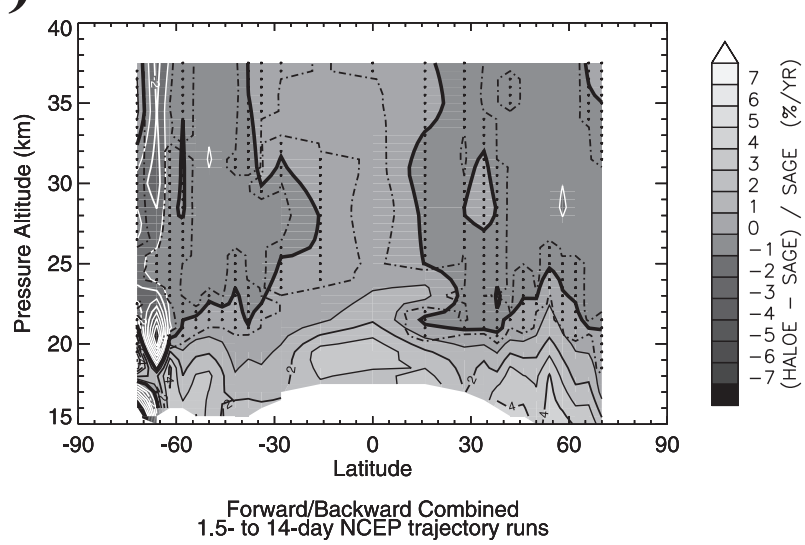

Figure 4. Trajectory mapping results of the drift in the ozone bias (see text for definition) of HALOE relative to SAGE II expressed in percent per year. The regions bounded by the dash-dot lines and containing stripes of vertical stars are regions not statistically significantly different from $0 \%$, as defined in the text. (a) HALOE V19 and SAGE II V6.00. (b) HALOE V18 and SAGE II V5.93. We find only small drifts of HALOE relative to SAGE II throughout the stratosphere in the latest versions of the retrievals (Figure 4a). The previous retrievals (Figure $4 b$ ) showed some drift of HALOE increasing relative to SAGE II in the lower stratosphere, a region where HALOE appeared biased low compared to SAGE II, as shown in Figure $3 b$.

data validation developed by Schoeberl and Lait [1992]. Their figure can be most directly compared with our Figure 3. The CM results reveal biases in the lower stratosphere (below the $500 \mathrm{~K}$ potential temperature surface or $\sim 22 \mathrm{~km}$ ) of HALOE more than $10 \%$ lower than SAGE II across most latitudes, in agreement with our results. CM also finds a region of slight bias with HALOE high in the tropical middle stratosphere. This region of high HALOE bias extends to higher altitudes through the northern midlatitudes. Again, we observe similar features in the TM results of Figure $3 \mathrm{~b}$. One feature that seems to have been eliminated in the current versions (Figure 3a) from the previous versions (e.g., Figure $3 b$ ) of the algorithms is an area of bias of HALOE high relative to SAGE II at $60^{\circ} \mathrm{S}$ in the middle and upper stratosphere. This region of bias appears in both the $\mathrm{CM}$ data and in the TM data for the HALOE V18 to SAGE II V5.93 comparison (Figure 3b) but does not appear in the HALOE V19 to SAGE II V6.00 comparison (Figure 3a).

[35] The observed pattern of SAGE II ozone observations high relative to most other ozone observations in the lower stratosphere has been a subject of prior investigation. Previous versions of the SAGE II retrieval algorithm contain problems related to aerosols, as identified by Steele and Turco [1997] and Cunnold et al. [1996]. In particular, Steele and Turco [1997] determine that the SAGE II retrieval algorithm contains errors that cause retrieved ozone values to be erroneously high (by as much as 15\%) in the presence of substantial volcanic aerosol. The eruption of Mount Pinatubo in 1991 created such conditions that affected the lower stratosphere through 1994. Just correcting for this aerosol retrieval problem, however, will not eliminate the observed differences between SAGE II and other instruments at low altitudes. As we observe in Figure 3a, even the latest version of the SAGE II retrieval, for which substantial changes have been made in light of the discoveries of problems with previous versions of the retrieval algorithm, reveals a lower stratospheric bias. Although not shown in this paper, we compute statistics for the period after the subsidence of the Pinatubo aerosols (1995-1999) separately to determine the impact of the aerosols on our results. We find that the pattern and magnitude of the bias during the 1995-1999 period are very similar to those represented in Figure 3a for the entire 8-year study period. Under background aerosol conditions, Steel and Turco [1997] suggest that the earlier SAGE II retrieval algorithm produced ozone values too low by up to $15 \%$ in the lower stratosphere. If this error were the only one affecting SAGE II ozone, the bias between SAGE II and HALOE would actually grow after correcting for it. Furthermore, we employ in our analysis the Wang-Cunnold criteria to effectively eliminate the influence of data contaminated by the presence of the Pinatubo aerosols during the period immediately following the eruption. SAGE II observations that would be affected by the retrieval error identified by Steele and Turco [1997] therefore are not included in our analysis, yet the bias remains apparent.

[36] Work presented by Bhatt et al. [1999] has demonstrated that the quality of HALOE V18 ozone profiles can be significantly affected by the presence of aerosols and cirrus clouds. In a comparison of HALOE data with ozonesondes, Bhatt et al. [1999] demonstrate that filtering the HALOE data for the presence of these aerosols can significantly improve the agreement, though the improvement typically occurs at altitudes below 120 mbar. Since most of the data presented in our study are gathered above 120 mbar, the screening criteria presented by Bhatt et al. [1999], though not employed in our study, would not affect our results. While the large disagreements present in the tropical lower stratosphere between HALOE and SAGE II ozone are disturbing, we have not at this time been able to devise a satisfactory explanation for their cause and leave this question as a topic for future research.

[37] Figure 4a shows the drift between HALOE V19 and SAGE II V6.00 ozone observations over the period December 1991 through October 1999 as determined with TM, while Figure $4 \mathrm{~b}$ shows the same statistic calculated from 
TM results generated with the HALOE V18 and SAGE II V5.93 data sets. We compute the mean drift by applying the simple linear trend model discussed earlier to the bias statistic of HALOE relative to SAGE II. Figure 5 shows an example of the bias versus time for a single bin of Figure $4 \mathrm{a}$ at $600 \mathrm{~K}$ from $32^{\circ}$ to $36^{\circ} \mathrm{S}$. The line represents the best fit to the data as computed using the drift calculation detailed above. Similar fits were found for bins at all latitudes and altitudes in our study to complete the construction of Figures $4 \mathrm{a}$ and $4 \mathrm{~b}$. In Figures $4 \mathrm{a}$ and $4 \mathrm{~b}$ the regions marked by dash-dotted lines and containing vertical stripes of stars represent regions of statistically insignificant differences: In these regions the drift in bias is smaller than the difference between the drift-in-bias statistic computed with the HALOE to SAGE II trajectory maps and that computed with the SAGE II to HALOE trajectory maps. TM results suggest essentially no drift of HALOE V19 relative to SAGE II V6.00 over the $\sim 15-40 \mathrm{~km}$ altitude range. These results represent a significant improvement relative to those found with the previous versions of these data sets.

[38] With the previous version of these data sets (Figure $4 b$ ) we observed drifts of $2-4 \%$ per year in the lower stratosphere with HALOE increasing relative to SAGE II. As this region is one in which HALOE V18 observations are observed to be lower than SAGE II V5.93, the drift suggests that the observations of the two instruments were drifting together over time. The presence of any drift between the two instruments raises cause for some alarm in efforts to evaluate trends in the ozone profile shape with SAGE V5.93. While the offsets between the new versions of these data sets are still potentially worrisome in and of themselves (Figure 3a), the lack of an observable drift between the data are encouraging for the use of these data in trend calculations. Looking at Figure $4 \mathrm{~b}$ in the lower tropical stratosphere, we see a large drift, whereas in Figure $4 \mathrm{a}$ in the same region, we see little to no drift. This difference suggests an improvement has been made in the SAGE II V6.00 retrieval of ozone in the lower stratosphere.

[39] SPARC [1998] also examines the drift of the HALOE V18 ozone data set relative to SAGE II V5.96. Findings reported in that study show drifts of $<0.5 \% / \mathrm{yr}$ at most latitudes and altitudes with a few exceptions: (1) $55^{\circ} \mathrm{S}$ where the drifts were $\sim 1 \% / \mathrm{yr}$ at most altitudes; (2) $15^{\circ} \mathrm{N}$ and $55^{\circ} \mathrm{S}$ near $25 \mathrm{~km}$ where the drifts were 1.5 to $2 \% / \mathrm{yr}$; and (3) $35^{\circ}-55^{\circ} \mathrm{S}$ and $15^{\circ}-55^{\circ} \mathrm{N}$ at $20 \mathrm{~km}$ where the drifts were $2-4 \% / y r$. We note that these conclusions were obtained through use of much smaller subsets of the data than are employed in the present study. Furthermore, with so few coincidences, the report could not identify any useful results in the tropics. Nevertheless, in those regions on which the SPARC report did comment, we find general agreement with our results of Figure $4 \mathrm{~b}$. Comparing the SPARC results with Figure 4a, however, we find few remaining regions where drifts of $>1 \% / y r$ exist.

[40] We examine the impact of the Wang-Cunnold criteria on our results using the latest versions of the two data sets. While we find that not employing the Wang-Cunnold criteria has only small impact on the RMS and bias statistics, we note that the drift statistic in the lower stratosphere becomes less coherent, and regions of $2-4 \% / y r$ drift appear in the tropical lower stratosphere (not shown). We

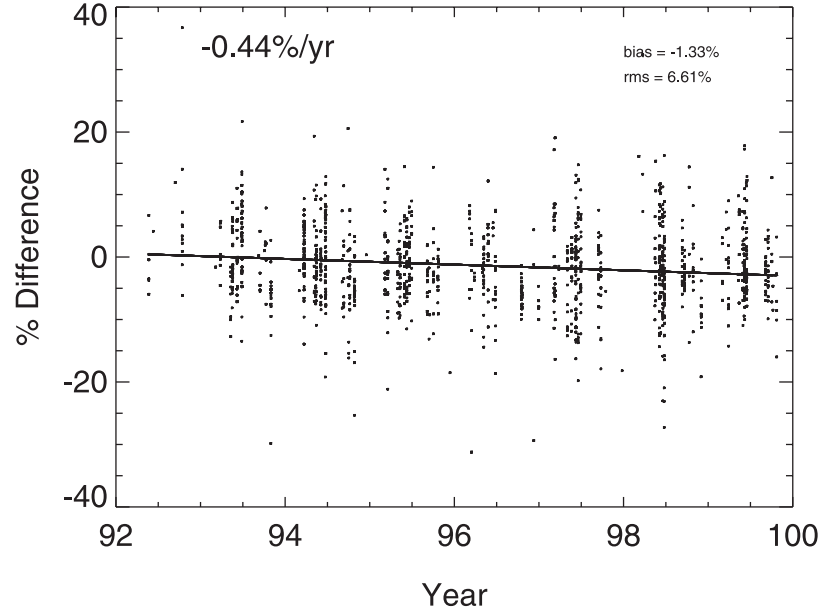

Figure 5. A scatterplot of the bias of HALOE relative to SAGE II (as defined in the text) as a function of time. The solid line represents the line of best fit. The slope of this line represents the drift statistic. The data for this plot come from trajectory mapping done on the $600 \mathrm{~K}$ potential temperature surface in the bin from $32^{\circ}$ to $36^{\circ} \mathrm{S}$.

therefore recommend continued use of the Wang-Cunnold criteria as outlined in Table 2.2 of SPARC [1998] for trend calculations.

[41] We also investigate the effect of the choice of meteorological wind field on our results. As shown by Morris et al. [1995], the choice of wind fields has the largest potential impact on the results of the trajectory calculations. We ran trajectories for the same set of months (March, May, June, September, October, and December) for the 7-year period from December 1991 to December 1997 using wind fields from the National Centers for Environmental Prediction (NCEP) and the UK Meteorological Office (UKMO). In this study we use HALOE V18 and SAGE II V5.93 data. With minor exceptions the results achieved with the UKMO meteorological data (not shown) were statistically the same as those achieved with the NCEP data. The good agreement between the results achieved with the two different wind fields enhances our confidence in our methodology and in the conclusions cited above. While we did not repeat this study with the latest versions of the data or through the extended study period (through October 1999), we do not believe our conclusions would change. The meteorological wind field choice does not appear to have a substantial impact on the results of this study.

\section{Summary and Conclusions}

[42] In conclusion, we have presented the most complete and wide-ranging comparison of the HALOE and SAGE II ozone profile data sets to date. Using TM, we are able to comment on the RMS differences, the biases, and the drift in those biases with time between these two important data sets over an 8-year period from 1991 to 1999 . We find typical RMS differences between HALOE V19 and SAGE II V6.00 of $4-12 \%$ through most of the stratosphere, with large differences $(>15 \%)$ in the tropical lower stratosphere (below $22 \mathrm{~km}$ ). The RMS statistic shows little improvement 
when compared with that generated by previous versions of the two data sets. The bias statistic shows generally small biases $(<4 \%)$ through most of the stratosphere, but large biases $(>10 \%$ with HALOE low compared to SAGE II) persisting in the tropical, subtropical, and midlatitude lower stratosphere (below $22 \mathrm{~km}$ and between $40^{\circ} \mathrm{S}$ and $40^{\circ} \mathrm{N}$ ). These results represent an improvement over previous versions of the data, particularly in the lower stratosphere between $40^{\circ}$ and $60^{\circ}$ in each hemisphere and in the mid to upper stratosphere in the tropics and midlatitudes, where earlier versions show the existence of larger biases between the two data sets. Finally, we see virtually no drift of HALOE V19 ozone observations relative to SAGE II V6.00. The results with SAGE V6.00 represent a significant improvement over previous versions of the data, particularly in the lower stratosphere where drifts of $2-4 \% / \mathrm{yr}$ are found relative to HALOE. The modifications to the SAGE II retrieval algorithm for V6.00 appear to have eliminated the previously observed drifts in the lower stratosphere. Should SAGE II fail before the launch of SAGE III, our results suggest that HALOE could provide a reliable data bridge between the two SAGE data sets.

[43] Where available, results from previous studies are compared to our TM statistics and show generally good agreement, confirming the integrity of the TM technique. TM results are not sensitive to the choice of meteorological wind field analysis, as demonstrated by the similar results generated using UKMO and NCEP wind fields for the same time period. Finally, for trend calculations we continue to recommend use of the Wang-Cunnold criteria for filtering of the SAGE II ozone data in the lower stratosphere due to contamination by Mount Pinatubo aerosols.

[44] Acknowledgments. The research presented in this paper has been supported through the following grants: the UARS Guest Investigator program and the EOS Validation program (grant NAG5-8490). Thanks to the entire SAGE II and HALOE teams for the ozone data products. Thanks to my colleagues in the Atmospheric Chemistry and Dynamics Branch at NASA Goddard Space Flight Center, in particular, Lynn Sparling, Stacey Hollandsworth-Frith, and Andrew Dessler for useful conversations and advice during the execution of this research.

\section{References}

Barath, F. T., et al., The upper atmosphere research satellite microwave limb sounder instrument, J. Geophys. Res., 98, 10,751-10,762, 1993.

Bhatt, P. P., E. E. Remsberg, L. L. Gordley, J. M. McInerney, V. G. Brackett, and J. M. Russell, An evaluation of the quality of Halogen Occultation Experiment ozone profiles in the lower stratosphere, J. Geophys Res., 104, 9261-9275, 1999.

Brinksma, E. J., et al., Validation of 3 years of ozone measurements over network for the detection of stratospheric change station Lauder, New Zealand, J. Geophys. Res., 105, 17,291-17,306, 2000.

Chu, W. P., M. P. McCormic, J. Lenoble, C. Brogniez, and P. Pruvost, SAGE II inversion algorithm, J. Geophys. Res., 94, 8339-8351, 1989.

Cunnold, D. M., H. Wang, W. P. Chu, and L. Froidevaux, Comparisons between Stratospheric Aerosol and Gas Experiment II and microwave limb sounder ozone measurements and aliasing of SAGE II ozone trends in the lower stratosphere, J. Geophys. Res., 101, 10,061-10,075, 1996.

Cunnold, D. M., H. J. Wang, L. W. Thomason, J. M. Zawodny, J. A. Logan, and I. A. Megretskaica, SAGE (version 5.96) ozone trends in the lower stratosphere, J. Geophys. Res., 105, 4445-4457, 2000.

Hollandsworth, S. M., R. D. McPeters, L. E. Flynn, W. Planet, A. J. Miller, and S. Chandra, Ozone trends deduced from combined Nimbus-7 SBUV and NOAA 11 SBUV/2 data, Geophys. Res. Lett., 22, 905-908, 1995.

Jackman, C. H., R. S. Stolarski, and J. A. Kaye, Two-dimensional monthly average ozone balance from limb infrared monitor of the stratosphere and stratospheric and mesospheric sounder data, J. Geophys. Res., 91, 11031116, 1986.

Lu, C. H., G. K. Yue, G. L. Manney, H. Jager, and V. A. Mohnen, Lagrangian approach for Stratospheric Aerosol and Gas Experiment (SAGE) II profile intercomparisons, J. Geophys. Res., 105, 45634572, 2000.

Mauldin, L. E. III, N. H. Zuan, M. P. McCormick, J. H. Guy, and W. R. Vaughn, Stratospheric Aerosol and Gas Experiment: A functional description, Opt. Eng., 24, 307-312, 1985.

Morris, G. A., et al., Trajectory mapping and applications to data from the Upper Atmosphere Research Satellite, J. Geophys. Res., 100, 16,491$16,505,1995$.

Morris, G. A., J. F. Gleason, J. Ziemke, and M. R. Schoeberl, Trajectory mapping: A tool for validation of trace gas observations, J. Geophys. Res., 105, 17,875-17,894, 2000.

Newchurch, M. J., D. M. Cunnold, and H. J. Wang, Stratospheric Aerosol and Gas Experiment II: Umkehr ozone profile comparisons, J. Geophys. Res., 100, 14,029-14,042, 1995.

Newman, P. A., D. J. Lamich, M. Gelman, M. R. Schoeberl, W. Baker, and A. J. Krueger, Meteorological atlas of the southern hemisphere lower stratosphere for August and September 1987, NASA Tech. Memo., TM4049, 1988.

Pierce, R. B., W. L. Grose, and J. M. Russell, III, Evolution of Southern Hemisphere air masses observed by HALOE, Geophys. Res. Lett., 21, 213-216, 1994

Randel, W. J., The evolution of winds from geopotential height data in the stratosphere, J. Atmos. Sci., 44, 3097-3120, 1987.

Reber, C. A., The Upper Atmosphere Research Satellite (UARS), Geophys. Res. Lett., 20, 1215-1218, 1993.

Rex, M., et al., In situ measurements of stratospheric ozone depletion rates in the Arctic winter 1991/1992: A Lagrangian approach, J. Geophys. Res., 103, 5843-5853, 1998.

Roche, A. E., J. B. Kumer, J. L. Mergenthaler, G. A. Ely, W. G. Uplinger, J. F. Potter, T. C. James, and L. W. Sterritt, The Cryogenic Limb Array Etalon Spectrometer (CLAES) on UARS: Experiment description and performance, J. Geophys. Res., 98, 10,763-10,775, 1993.

Russell, J. M., et al., The Halogen Occultation Experiment, J. Geophys. Res., 98, 10,777-10,797, 1993.

Schoeberl, M. R., and L. R. Lait, Conservative-coordinate transformations for atmospheric measurements, in Proceedings of the International School of Physics: The Use of EOS for Studies of Atmospheric Physics, pp. 419-430, Elsevier Sci., New York, 1992.

Schoeberl, M. R., and L. Sparling, Trajectory modeling, in Proceedings of the International School of Physics: Diagnostic Tools in Atmospheric Physics, edited by G. F. A. G. Visconti, pp. 289-305, Elsevier Sci., New York, 1994.

Steele, H. M., and R. P. Turco, Separation of aerosol and gas components in the Halogen Occultation Experiment and Stratospheric Aerosol and Gas Experiment (SAGE) II extinction measurements: Implications for SAGE II ozone concentrations and tends, J. Geophys. Res., 102, 19,66519,681, 1997.

Stolarski, R. S., P. Bloomfield, R. D. McPeters, and J. R. Herman, Total ozone trends deduced from NIMBUS 7 TOMS data, Geophys. Res. Lett., 18, 1015-1018, 1991.

Stratospheric Processes and Their Role in Climate (SPARC), Assessment of Trends in the Vertical Distribution of Ozone, Rep. 1, edited by N. Harris, R. Hudson, and C. Phillips, World Meteorol. Organ., Geneva, 1998.

Sutton, R. T., H. Maclean, R. Swinbank, A. O'Neill, and F. W. Taylor, High-resolution stratospheric tracer fields estimated from satellite observations using Lagrangian trajectory calculations, J. Atmos. Sci., 51, 2995-3005, 1994.

Veiga, R. E., D. M. Cunnold, W. P. Chu, and M. P. McCormick, Stratospheric Aerosol and Gas Experiments I and II comparisons with ozonesondes, J. Geophys. Res., 100, 9073-9090, 1995.

J. Gleason and M. R. Schoeberl, Mail Code 916, NASA Goddard Space Flight Center, Greenbelt, MD 20771, USA. (gleason@redwind.gsfc.nasa. gov; schom@zephyr.gsfc.nasa.gov)

G. A. Morris, Department of Physics and Astronomy, MS-61, Rice University, P.O. Box 1892, Houston, TX 77251-1892, USA. (gmorris@) rice.edu)

J. M. Russell III and M. P. McCormick, Center for Atmospheric Sciences, Hampton University, 23 Tyler Street, Hampton, VA 23668, USA. (james.russell@hamptonu.edu) 